\title{
Overexpression of stearoyl-CoA desaturase 1 in bone marrow mesenchymal stem cells enhance the expression of induced endothelial cells
}

\author{
Yuanshan Lu', Zihui Zhou², Jie Tao ${ }^{2^{*}}$, Bang Dou ${ }^{3}$ Mingjie Gao ${ }^{2}$ and Yue Liu²
}

\begin{abstract}
Background: Bone marrow mesenchymal stem cells (BM-MSCs) are capable of differentiating into endothelial cells in vitro and acquire major characteristics of mature endothelial-like expression of VWF and CD31. SFAs and lipid oxidation products have been linked with postprandial endothelial dysfunction. Consumption of SFAs impairs arterial endothelial function, while a Mediterranean-type MUFA-diet has a beneficial effect on endothelial function by producing a decrease in levels of VWF, TFPI and PAI-1. Stearoyl-CoA desaturase 1 (SCD1), which converts SFA to MUFA, is involved in the cellular biosynthesis of MUFAs from SFA substrates. High expression of SCD1 is corresponded with low rates of fatty acid oxidation, therefore it might reduce inflammatory responses and be beneficial for the growth of induced endothelial cells. Overexpression of SCD1 in BM-MSCs might increase the growth of induced endothelial cells. The goal of this research is to study the relationship between overexpression of SCD1 and the expression of induced endothelial cells in BM-MSCs in vitro.
\end{abstract}

Methods: The gene SCD1 was integrated into a lentiviral vector, and then 293 T cells were transfected by the connected product to produce a packaged virus. BM-MSCs were infected by the packaged virus. Cell culture and endothelial induction were performed. Fluorescent quantitative PCR of CD31, VWF and VE-cad was performed after 1 week and 2 weeks to test the growth of induced endothelial cells.

Results: The mRNA amount of CD31, VWF and VE-cad of the SCD1 overexpressed group was statistically higher than that of the empty vector (EV) group and that of the normal group after 1 week and 2 weeks, respectively $(p<0.05)$. Immunocytochemical staining of CD31 or vWF was detected by visualizing red color.

Conclusions: This study suggested that overexpression of SCD1 in BM-MSCs could increase the expression of induced endothelial cells in vitro.

Keywords: Stearoyl-CoA desaturase 1, Bone marrow mesenchymal stem cells, Endothelial

\section{Background}

Stearoyl-CoA desaturase 1 (SCD1), known as a $\Delta 9$ desaturase, is an integral membrane protein anchored in the endoplasmic reticulum [1]. SCD1 converts saturated fatty acids (SFAs) to monounsaturated fatty acids (MUFAs), which make up the primary storage of unsaturated fatty acids in human adipose tissue [2].

An inverse relationship between endothelial function and SFA has been shown in healthy adults [3]. Plasma

\footnotetext{
*Correspondence: taojie123@sjtu.edu.cn

2Department of Orthopedics, Shanghai First People's Hospital, School of Medicine, Shanghai Jiao Tong University, 100, Haining Road, Shanghai 200080, China

Full list of author information is available at the end of the article
}

SFA, which partly reflects dietary fat quality, has an important impact on endothelial function. Consumption of SFAs reduces the anti-inflammatory properties of HDL and impairs endothelial function [4]. In healthy adolescents, impaired endothelial function is significantly associated with high level of soluble ICAM-1, HOMA-IR and SFA [5].

Mesenchymal stem cells (MSCs) are multipotent stem cells that can be isolated from many human adult or fetal tissues. MSCs were found to differentiate into cartilage, bone, fat, muscle, and other connective tissues [6,7]. In endothelial differentiation system, human bone marrowderived (CD105+, CD29+, CD34-) MSCs are capable of 
differentiating into endothelial cells in vitro and acquire major characteristics of mature endothelial-like expression of von Willebrand factor (vWF) and CD31 [8]. This will make bone marrow mesenchymal stem cells (BM-MSCs) attractive candidates for the development of autologous tissue graft. Overexpression of SCD1 in BM-MSCs might have advantages for the expression of induced endothelial cells by reducing the the amount of SFAs in human bodies.

Up to now, there has been no report in the literature of the relationship between the overexpression of SCD1 and the expression of induced endothelial cells in BM-MSCs. The goal of this research is to study the relationship between the overexpression of SCD1 and the expression of induced endothelial cells in BM-MSCs in vitro.

\section{Results}

\section{Vector construction and virus packaging}

GFP fluorescence imaging showed that the $293 \mathrm{~T}$ cells were transfected by viral vector successfully after $48 \mathrm{~h}$ (Figure 1a), and the packaged virus infected $293 \mathrm{~T}$ cells successfully after $48 \mathrm{~h}$ (Figure $1 \mathrm{~b}$ ). The titer of viral vector was calculated according to the results of flow cytometry (Figure 1d). The title calculation is as follows: titer $(293 \mathrm{~T}$-transducing units $/ \mathrm{ml})=100,000$ (target $293 \mathrm{~T}$ cells $) \times(\%$ of GFP-positive cells/100)/volume of supernatant $(\mathrm{ml})$. The titer of this experiment is $5.17 \times 10^{8} \mathrm{TU} /$ $\mathrm{ml}$. BM-MSCs were infected by the packaged virus successfully (Figure 1c). The results of flow cytometry on BM-MSCs (Figure 1e) showed that $87.2 \%$ of the total cells were GFP positive.

\section{Overexpression of SCD1}

RT-PCR showed that the amount of SCD1 mRNA in the SCD1 overexpressed group was $8.86 \pm 0.94$ and that the amount of the empty vector (EV) group was $1.00 \pm 0.09$. The expression of SCD1 mRNA of the SCD1 overexpressed group is statistically higher than that of the EV group $(\mathrm{p}<$ 0.01) (Figure 2a). Enzyme activity measurement showed that the activity of SCD1 in the SCD1 overexpressed group was $35.87 \pm 3.11$ and that the activity of the empty vector (EV) group was $23.75 \pm 2.16$. SCD1 activity of the SCD1 overexpressed group is statistically higher than that of the EV group $(\mathrm{p}<0.01)$ (Figure $2 \mathrm{~b})$. A western blot of SCD1 showed that the concentration of SCD1 in the SCD1 overexpressed group was higher than that of the EV group (Figure 3).

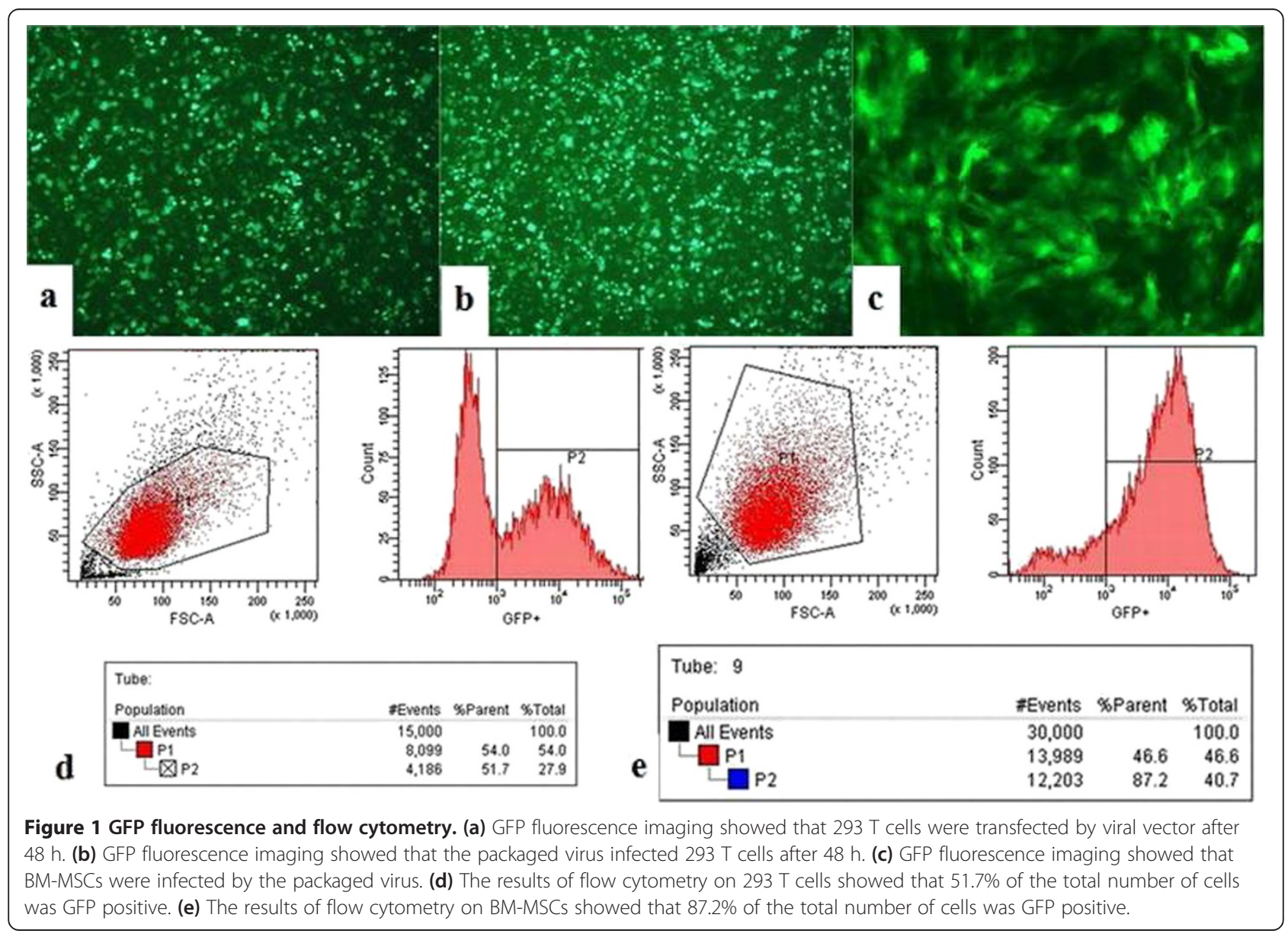



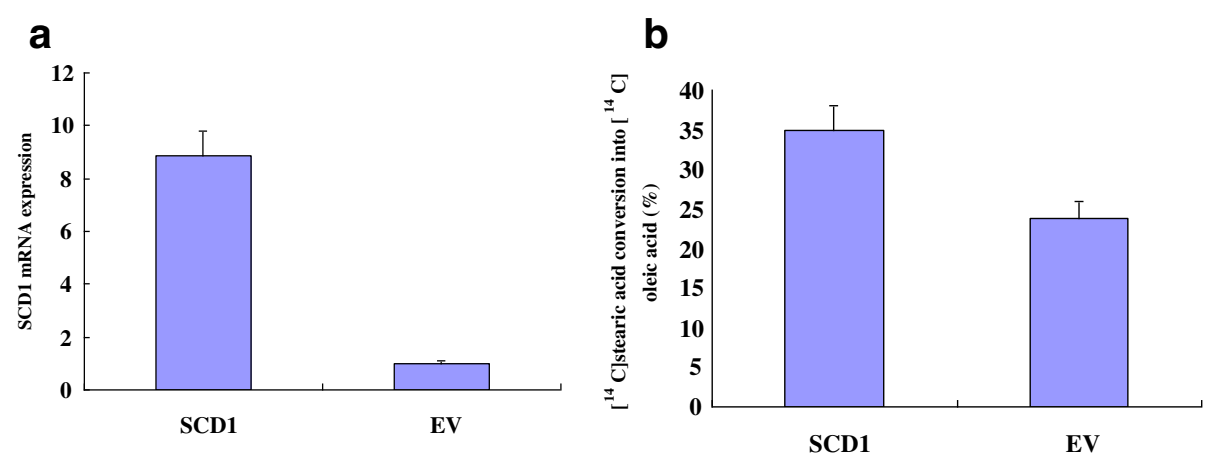

Figure 2 Realtime PCR and activity results of SCD1. Realtime PCR and enzyme activity analysis results showed that the amount of SCD1 mRNA (a) and enzyme activity (b) of the SCD1 overexpressed group was higher than that of the EV group $(p<0.01)$.

\section{Endothelial cell induction}

The results of fluorescent quantitative PCR (Table 1, Figure 4) showed that the mRNA amount of CD31 of the SCD1 overexpressed group was higher than that of the EV group after 1 week and 2 weeks $(\mathrm{p}<0.05)$, and was significantly higher than that of the normal group after 1 week and 2 weeks $(\mathrm{p}<0.01)$. The mRNA amount of vWF of the SCD1 overexpressed group was higher than that of the EV group after 1 week and 2 weeks $(\mathrm{p}<0.05)$ and that of the normal group after 2 weeks $(\mathrm{p}<0.05)$, and was significantly higher than that of the normal group after 1 week $(p<0.01)$. The mRNA amount of VE-cad of the SCD1 overexpressed group was significantly higher than that of the EV group and that of the normal group after 1 week and 2 weeks $(\mathrm{p}<0.01)$. Meanwhile, vWF and CD31 staining could be detected and the positive staining is visualized by red color (Figure 5a, b, c for vWF and d, e, f for CD31).

\section{Discussion}

SCD1 has been regarded as the switch between fatty acid storage and consumption as well as in promoting or preventing lipid-induced disorders $[9,10]$. SCD1 is involved in the cellular biosynthesis of MUFAs from SFA substrates. The substrates of SCD1 are mainly stearoyl-CoA (C18:0) and palmitoyl-CoA (C16:0), which are desaturated to oleoyl-CoA (C18:1) and palmitoleoyl-CoA (C16:1), respectively. SCD1 prefers to convert stearate to oleate rather than palmitate to palmitoleate [11], both of which make up the primary storage of unsaturated fatty acids in human adipose tissue [2]. The major MUFAs generated by SCD1 represent the main substrates for synthesis of triglycerides, cholesterol esters and phospholipids. Consistent with its role as a key player in metabolic control, SCD1 activity is tightly regulated, being decreased by unsaturated fatty acids (UFAs) and increased by SFAs [12].

MSCs were found to differentiate into cartilage, bone, fat, muscle, and other connective tissues [6,7] depending on the culture conditions, which include supplementation of lineage-specific inducing agents as well as hormones and growth factors. Studies have demonstrated that mesoderm-derived MSCs originate from precursors with angiogenic potential, called mesenchymomagioblasts, which are identified as MS-CFCs with the potential to differentiate into both MSCs and endothelial cells [13]. In endothelial differentiation system, human bone marrowderived (CD105+, CD29+, CD34-) MSCs are capable of differentiating into endothelial cells in vitro and acquire major characteristics of mature endothelial-like expression of vWF and CD31 [8]. In addition, MSCs give rise to

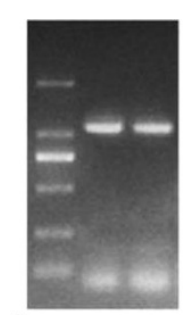

a

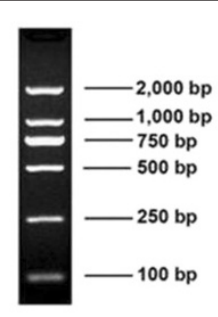

b

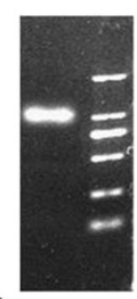
$b$

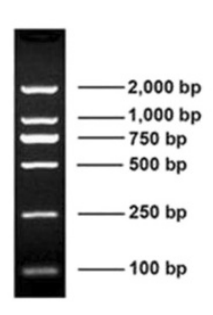

Figure 3 Vector construction of SCD1 overexpression. (a) An electrophoresis map of the PCR products of SCD1. (b) An electrophoresis map of the PCR products of connected vector PCDH-SCD1. (c) Western blot of SCD1 showed that the concentration of SCD1 in the SCD1 overexpressed group is higher than that in the EV group. 
Table 1 Results of fluorescent quantitative PCR (mean \pm SD)

\begin{tabular}{lccccc}
\hline & $\begin{array}{c}\text { SCD1 } \\
\text { (repeating times) }\end{array}$ & $\begin{array}{c}\text { EV } \\
\text { (repeating times) }\end{array}$ & $\begin{array}{c}\text { Normal } \\
\text { (repeating times) }\end{array}$ & $\begin{array}{c}\text { P value } \\
\text { SCD1 vs EV }\end{array}$ & $\begin{array}{c}\text { P value } \\
\text { SCD1 vs normal }\end{array}$ \\
\hline CD31 (1 week) & $1.70 \pm 0.18(6)$ & $1.39 \pm 0.23(6)$ & $1.15 \pm 0.02(6)$ & $0.013^{*}$ & $<0.01^{* *}$ \\
CD31 (2 weeks) & $6.78 \pm 0.93(6)$ & $5.51 \pm 1.05(6)$ & $4.37 \pm 0.54(6)$ & $0.025^{*}$ & $<0.01^{* *}$ \\
VWF (1 week) & $3.21 \pm 0.36(6)$ & $2.80 \pm 033(6)$ & $1.87 \pm 0.27(6)$ & $0.033^{*}$ & $<0.01^{* *}$ \\
VWF (2 weeks) & $6.25 \pm 0.56(6)$ & $5.21 \pm 0.57(6)$ & $5.80 \pm 0.20(6)$ & $0.048^{*}$ & $<.047^{*}$ \\
VE-cad (1 week) & $4.11 \pm 0.51(6)$ & $1.70 \pm 0.07(6)$ & $1.49 \pm 0.05(6)$ & $<0.01^{* *}$ & $<0.01^{* *}$ \\
VE-cad (2 weeks) & $5.36 \pm 0.07(6)$ & $3.37 \pm 0.19(6)$ & $3.24 \pm 0.16(6)$ & $<0.01^{* *}$ & $<0.01^{* *}$ \\
\hline
\end{tabular}

${ }^{*} p$ value $<0.05$ expressed mRNA expression of CD31, vWF or VE-cad of the SCD1 overexpressed group was statistically higher than that of the EV group or that of the normal group after 1 week and 2 weeks.

${ }^{* *} \mathrm{p}$ value $<0.01$ expressed mRNA expression of CD31, vWF or VE-cad of the SCD1 overexpressed group was statistically significantly higher than that of the EV group or that of the normal group after 1 week and 2 weeks.

hematopoiesis-supportive stroma and contribute to the formation of the hematopoietic stem cell niche $[14,15]$ and vascular wall [16].

In this study, GFP fluorescence imaging showed that BM-MSCs were infected by the packaged virus, and RT-PCR results showed that the expression of SCD1 mRNA of the SCD1 overexpressed group is higher than that of the EV group $(\mathrm{p}<0.01)$. So overexpression of SCD1 in BM-MSCs was achieved successfully. Commonly used markers of the endothelium include CD31 and vWF [17]. Vascular endothelial cadherin (VE-cad), a putative member of the type II subfamily $[18,19]$ is specifically expressed in endothelial cells and is not found in any other cell type $[20,21]$. In order to test the growth of induced endothelial cells, CD31, vWF and VE-cad in MSCs were assayed, and the results of fluorescent quantitative PCR suggested that the mRNA amount of CD31, vWF, VE-cad of the SCD1 overexpressed group was statistically higher than that of the EV group and that of the normal group after 1 week and 2 weeks $(\mathrm{p}<0.05)$. This result indicated that overexpression of SCD1 in BM-MSCs could increases the expression of induced endothelial cells in vitro.

SFAs and lipid oxidation products have been linked with postprandial endothelial dysfunction $[4,22]$ and atherosclerotic disease. Diets rich in SFAs [23] or oxidized fatty acids [24] accelerate the formation of atherosclerotic lesions in animals. High intake of SFAs has been associated with an increased incidence of coronary heart disease
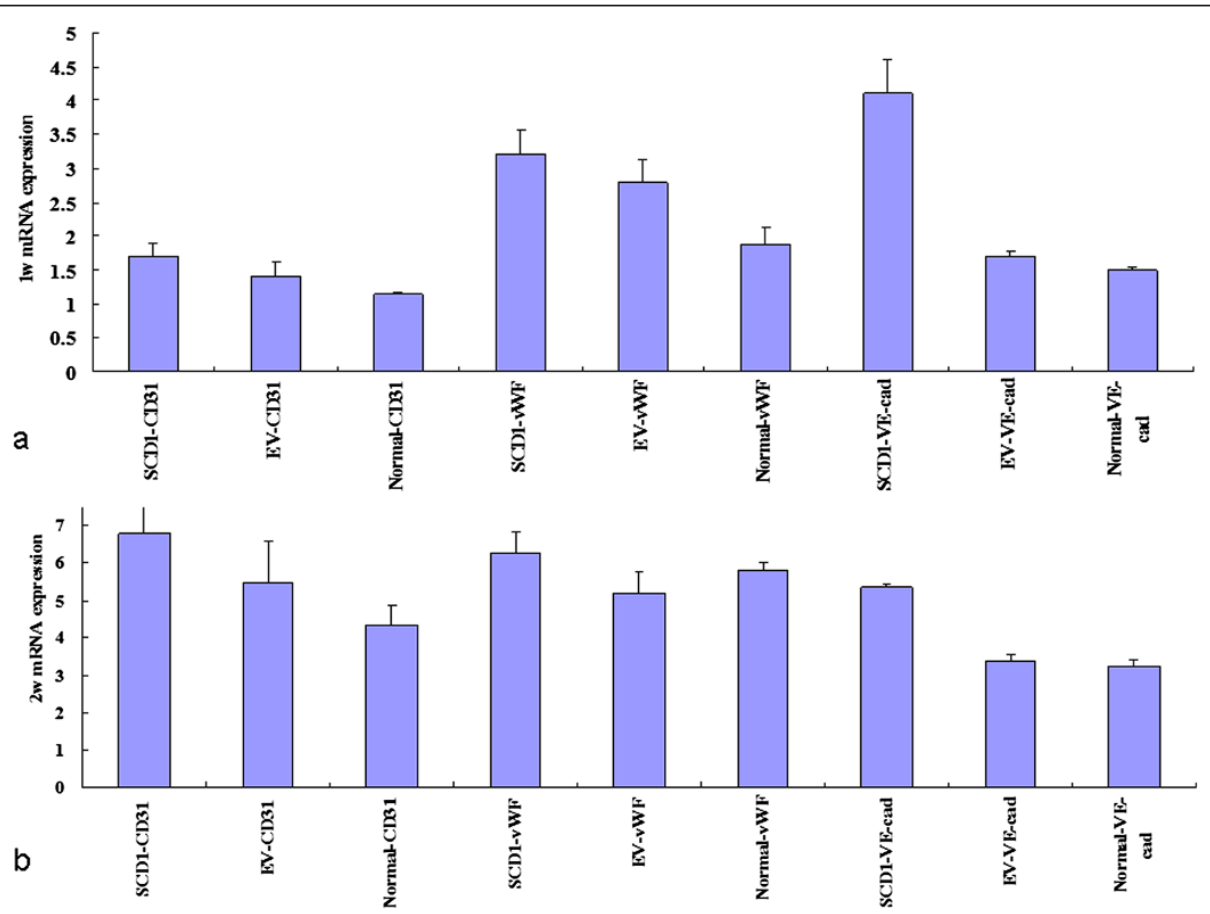

Figure 4 Realtime PCR results of CD31, vWF and VE-cad. Realtime PCR results showed that the mRNA amount of CD31, vWF and VE-cad of the SCD1 overexpressed group was higher than that of the EV group and that of the normal group after 1 week (a) and 2 weeks (b) $(p<0.05)$. 

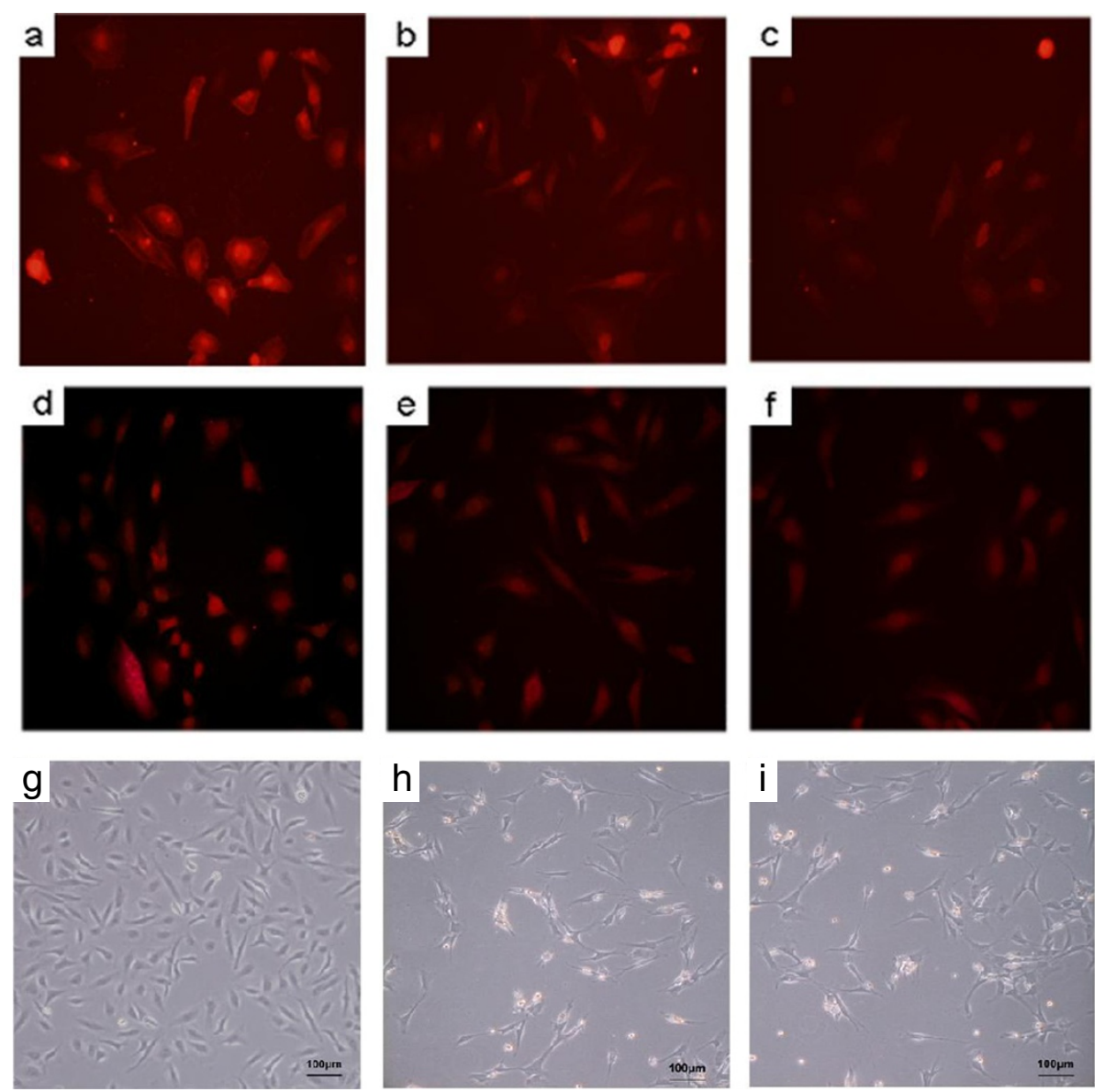

Figure 5 Immunostaining of CD31 and vWF. The MSCs was induced into endothelial cells which were also transfected with/without SCD1 gene or empty-vector. Immunocytochemical staining was performed using CD31 and VWF antibodies. Positive staining is visualized by red color for vWF (Figure 5a, b, c) or CD31 (Figure 5d, e, f). a/d was referred to SCD1 overexpressed group, b/e was normal group, c/f was empty-vector group. Microscopic image showed that SCD1 overexpressed group (g) had more endothelial cells than normal group (h) and empty-vector group (i).

(CHD), whereas high intake of MUFAs has been associated with a protective effect $[25,26]$. Dietary fats can modify CHD risk by their effect on plasma LDL and HDL cholesterol levels [27]. Consumption of SFAs reduces the anti-inflammatory potential of HDL and impairs arterial endothelial function. Consumption of a Mediterraneantype MUFA-diet produces a decrease in plasma levels of vWF, TFPI and PAI-1 plasma levels in young healthy males. Given that these substances are of endothelial origin, it could be suggested that MUFA of the diet has a beneficial effect on endothelial function [28].

A large panel of inflammatory genes are regulated by SFAs. A possible role of SFAs in inflammation has been demonstrated in vitro. When stimulating human cells with palmitic acid, the gene expression and protein production of IL-6 increased [29,30]. The exact mechanisms for these effects are unknown but proposed involved molecules are nuclear factor (NF)- $\mathrm{kB}$ and protein kinase $C$ [30]. SFAs represent potential contributors to the vascular inflammation in subjects with metabolic syndrome [31]. In the liver, SCD1 deficiency sensitizes cells to injury [32]. In human myotubes, overexpression of SCD1 enhances triglyceride synthesis and prevents inflammatory and ER-stress responses to palmitate [33]. Overexpression of SCD1 in BM-MSCs might increase the growth of induced endothelial cells by decreasing the amount of SFAs and preventing inflammatory and ER-stress responses.

Study has shown that SCD1 deficiency increases the rate of $\beta$-oxidation in soleus and red gastrocnemius muscles by activating of the AMP-activated protein kinase (AMPK) pathway [34,35]. AMPK leads to phosphorylation and inactivation of acetyl-CoA carboxylase resulting in decreased malonyl-CoA content [36]. Malonyl-CoA is both an intermediate in de novo synthesis of fatty acids and an allosteric inhibitor of carnitine palmitoyltransferase 1 (CPT1), the enzyme that transfers long-chain acyl$\mathrm{CoA}$ molecules from the cytosol to the mitochondria 
where they are oxidized [37]. A decrease in the cellular levels of malonyl-CoA in the liver and skeletal muscles of SCD1-/- mice would thus derepress CPT1, resulting in increased fatty acid oxidation and downregulation of fatty acid synthesis [37]. High expression of SCD1 is corresponded with low rates of fatty acid oxidation (decreased AMPK activity) [38]. Less fat acid oxidation might reduce inflammatory responses and be beneficial for the growth of induced endothelial cells.

SCD1 deficiency results in increased the phosphorylation of the cAMP response element binding protein (CREBP) and the activation of the peroxisome proliferator activated receptor $\gamma$ (PPAR $\gamma$ ) coactivator-1a (PGC-1a) transcription factor through activation of the $\beta 3$ adrenergic receptor pathway [39], resulting in increased activation of uncoupling protein 1 (UCP1) in BAT of SCD1-/- mice. Increased UCP1 expression uncouples oxidative respiration from ATP synthesis, thereby increasing the rate of basal thermogenesis and consequently, whole body energy expenditure, in SCD1-/- mice [39]. Therefore, high expression of SCD1 might decrease the energy expenditure of cells, helping the growth of induced endothelial cells.

It has been demonstrated that SCD1 modulates the passage of cycling cells through the G1/S boundary and the entry into the apoptotic program, and SCD1 regulates mitogenesis by modulating the rate of fatty acid synthesis, by preventing the toxic accumulation of SFA, and by controlling the supply of MUFA substrates required for lipid biosynthesis and cell proliferation [40]. Overexpression of SCD1 in BM-MSCs might contribute to proliferation of induced endothelial cells by modulating the passage of cycling cells [41].

\section{Conclusion}

This study suggested that overexpression of SCD1 in BM-MSCs could increase the expression of induced endothelial cells in vitro by showing that the mRNA amount of CD31, vWF and VE-cad of BM-MSCs increased after overexpression of SCD1 in vitro. However, the mechanism by which SCD1 increases the expression of induced endothelial cells of BM-MSCs needs further study.

\section{Methods}

\section{Vector system}

The lentiviral vector system (Tronolab) includes $\mathrm{pCDH}$, psPAX2, and pMD. pCDH can express green fluorescent protein (GFP). Both psPAX2 and pMD contain essential elements for virus packaging.

\section{Vector construction and virus packaging}

Using SCD1 gene purchased from OriGene Technologies (SC108809) as a template, fragments of the SCD1 gene were amplified (Figure 3a) using primers capped with
BamHI and EcoRI recognition sequences (Table 2 SCD1*). This fragment was then inserted at a unique BamHI site and EcoRI site in the shuttle vector $(\mathrm{pCDH})$ to construct the pCDH-SCD1 plasmid. E. coli was transformed with $\mathrm{pCDH}-\mathrm{SCD} 1$ and cultured overnight at $37^{\circ} \mathrm{C}$. Polymerase chain reaction (PCR) of the connected product was performed (Figure $3 \mathrm{~b}$ ), and the construct was confirmed by DNA sequencing. $293 \mathrm{~T}$ cells were transfected by pCDHSCD1, psPAX2 and pMD. The virus supernatant was collected after $48 \mathrm{~h}$ of cultivation. A concentrated solution of virus was made with ultra centrifugation and purification, and the titer of virus was determined. BM-MSCs were then infected by the packaged virus. GFP-positive cells were selected by flow cytometry.

\section{Western blot}

Cells were lysed in RIPA buffer, and protein extraction was carried out on ice. Protein concentration was determined by BCA assay. Eight $\mu \mathrm{l}$ of total protein lysate were mixed with SDS loading buffer, and proteins were separated by electrophoresis on 12\% SDS-PAGE. After that, proteins were transferred onto PVDF membranes. After blocking with 5\% skim milk in PBS for 2 hours, membranes were washed and incubated sequentially with primary anti-SCD1 antibody (ab 19862; Abcam, Cambridge, USA) and anti-mouse secondary antibody-horseradish conjugate (Abcam). Western blots were developed colorimetrically (Figure 3c).

\section{Overexpression of SCD1}

Total RNA was extracted from BM-MSCs using Trizol (Invitrogen). Prior to real time PCR (RT-PCR), the RNA was treated with DNase I. The purified RNA was used for first-strand cDNA synthesis, and reverse transcription was performed using M-MLV reverse transcriptase with oligo-dT primers according to the manufacturer's instructions (Promega). The 170-bp fragment of the SCD1 gene was amplified using primers (Table $2 \mathrm{SCD} 1 * *$ ), with $\beta$-actin (Table 2) used as an internal control gene.

\begin{tabular}{|c|c|}
\hline Gene & Primer sequence \\
\hline \multirow[t]{2}{*}{$\mathrm{SCD} 1^{*}$} & 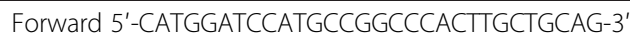 \\
\hline & Reverse 5'-TATGAATTCTCAGCCACTCTTGTAGTTTC-3' \\
\hline \multirow[t]{2}{*}{$\beta$-actin } & Forward 5'-CTCCATCCTGGCCTCGCTGT-3' \\
\hline & Reverse 5'-GCTGTCACCTTCACCGTTCC-3' \\
\hline \multirow[t]{2}{*}{$\mathrm{SCD} 1^{* *}$} & Forward 5'-CAGTGTGTTCGTTGCCACTT-3'- \\
\hline & Reverse 5'-GGTAGTTGTGGAAGCCCTCA-3'- \\
\hline
\end{tabular}

*Primer used to draw SCD1 fragments for $\mathrm{PCDH}-\mathrm{SCD} 1$ construction from SCD1 gene.

**Primer used to monitor the expression of SCD1 in BM-MSCs. 


\section{Determination of Scd 1 activity}

We evaluated Scd1 activity by measuring the conversion of $\left[{ }^{14} \mathrm{C}\right]$ stearic acid into $\left[{ }^{14} \mathrm{C}\right]$ oleic acid after overexpression SCD1. Cells were incubated with $3 \mu \mathrm{M}(0.25 \mu \mathrm{Ci} / \mathrm{dish}$ of $\left[{ }^{14} \mathrm{C}\right]$ stearic acid) for $6 \mathrm{~h}$ at $37^{\circ} \mathrm{C}$ in $5 \% \mathrm{CO}_{2}$ incubator. Cells were collected and total lipids were extracted according to Bligh and Dyer method [42]. Lipids were saponified and esterified. Radiolabelled fatty acid methyl esters were separated by RP-HPLC and detected on line by a radioisotope detector (Packard Flow Scintillation Analyser, PerkinElmer Life Sciences Inc., Wellesley, MA). The $\left[{ }^{14} \mathrm{C}\right]$ oleic acid/ $\left(\left[{ }^{14} \mathrm{C}\right]\right.$ oleic and stearic acids $)$ ratio was determined as Scd activity $[43,44]$.

\section{Endothelial cell induction}

BM-MSCs were cultured in Dulbecco's modified Eagle's medium (DMEM) containing 10\% fetal bovine serum (FBS) at $37^{\circ} \mathrm{C}$ in a humidified atmosphere of $5 \% \mathrm{CO}$ and 95\% air, according to the standard procedure. The cell lines were routinely passaged using an enzymatic solution consisting of $0.25 \%(\mathrm{w} / \mathrm{v})$ trypsin for $5 \mathrm{~min}$ at $37^{\circ} \mathrm{C}$. The third generation cells, with $1 \times 10^{4}$ cells/well, were transferred onto a 12-well plate. After $24 \mathrm{~h}$, endothelial cell induction was performed with induction medium (low glucose DMEM containing 10\% FBS). Fluorescent quantitative PCR of CD31, vWF and VE-cad was performed after 1 week and 2 weeks to test the growth of induced endothelial cells.

\section{Immunostaining}

A total of $1 \times 10^{5}$ cells were incubated at $4{ }^{\circ} \mathrm{C}$ with a mouse mono-clonal anti-CD31 antibody (Southern Biotechnology, AL, USA). After $45 \mathrm{~min}$, the cells were washed with PBS and stained with an Alexa 488-conjugated goat anti-mouse anti-body (Invitrogen) for $30 \mathrm{~min}$ at $4^{\circ} \mathrm{C}$ in the dark. The cells were also rehydrated and incubated for $2 \mathrm{~h}$ with anti-von Willebrand factor (vWF) (DakoCytomation, clone F8/86). Subsequently, rabbit-anti-mouse immunoglobulin (DakoCytomation) was added for $45 \mathrm{~min}$. Sections and cells were photographed using a Sony color video camera.

\section{Fluorescent quantitative PCR}

Total RNA extraction was performed according to the instruction of RNA extraction kit (QIAGEN). RNA reverse transcription was performed following the instruction of M-MLV (Promega). Fluorescent quantitative PCR was then performed to detect the expression of CD31, vWF and VE-cad, with $\beta$-actin used as an internal control gene. Primer sequences were as follows (Table 3). The amount of PCR copies was obtained according to the standard curve.
Table 3 Primer sequences of CD31, vWF and VE-cad

\begin{tabular}{cl}
\hline Gene & \multicolumn{1}{c}{ Primer sequence } \\
\hline$\beta$-actin & Forward 5'-ATCGTGGGCCGCCCTAGGCA-3' \\
& Reverse 5'-TGGCCTTAGGGTTCAGAGGGG-3' \\
VWF & Forward 5'-CCCACCGGATGGCTAGGTATT-3' \\
& Reverse 5'-GAGGCGGATCTGTTGAGGTT-3' \\
CD31 & Forward 5'-GGACTGGCCCTGTCACGTT-3' \\
& Reverse 5'-TTGTTCATGGTGCCAAAACACT-3' \\
VE-cad & Forward 5'-GGCCAACGAATTGGATTCTA-3' \\
& Reverse 5'-GTTACTGGCACCACGTCCT-3' \\
\hline
\end{tabular}

\section{Statistical analysis}

All experiments were repeated six times. All values were presented as the means \pm SD. Statistically significant differences between groups were assessed by an unpaired Student's t-test. Differences of $\mathrm{p}<0.05$ were considered to be statistically significant.

\section{Competing interests}

The authors declare that they have no competing interests.

\section{Authors' contributions}

YL (Yuanshan Lu) and JT designed the experiment and protocols and wrote the manuscript. YL (Yuanshan Lu) performed Vector construction and virus package, BM-MSCs infection, flow cytometry analysis. ZZ participated in cell cultivating. BD performed real-time PCR, western blot. MG performed Immunostaining. YL performed statistical analysis. YL (Yuanshan Lu) and JT interpreted the data. All authors read and approved the final manuscript.

\section{Acknowledgments}

This work was funded by The National Natural Science Fundation of China (No. 81371963); the Shanghai Hygiene Bureau (NO. 2010159), the Shanghai Jiao Tong University School of Medicine (NO. YZ1076) and the Medical Climbing Project of the Songjiang Science Commission of Shanghai (NO. 2011PD05).

\section{Author details}

'Department of Transfusion, Shanghai First People's Hospital, School of Medicine, Shanghai Jiao Tong University, 100, Haining Road, Shanghai 200080, China. ${ }^{2}$ Department of Orthopedics, Shanghai First People's Hospital, School of Medicine, Shanghai Jiao Tong University, 100, Haining Road, Shanghai 200080, China. ${ }^{3}$ Department of Orthopedics, Shanghai First People's Hospital Songjiang Branch, School of Medicine, Shanghai Jiao Tong University, 746, Zhongshan Middle Road, Shanghai 201600, China.

Received: 20 November 2013 Accepted: 11 March 2014 Published: 20 March 2014

\section{References}

1. Man WC, Miyazaki M, Chu K, Ntambi JM: Membrane topology of mouse stearoyl-CoA desaturase 1. J Biol Chem 2006, 281(2):1251-1260.

2. Insull W Jr, Bartsch GE: Fatty acid composition of human adipose tissue related to age, sex, and race. Am J Clin Nutr 1967, 20(1):13-23.

3. Sarabi M, Vessby B, Millgard J, Lind L: Endothelium-dependent vasodilation is related to the fatty acid composition of serum lipids in healthy subjects. Atherosclerosis 2001, 156(2):349-355.

4. Nicholls SJ, Lundman P, Harmer JA, Cutri B, Griffiths KA, Rye KA, Barter PJ, Celermajer DS: Consumption of saturated fat impairs the antiinflammatory properties of high-density lipoproteins and endothelial function. J Am Coll Cardiol 2006, 48(4):715-720.

5. Chen Y, Osika W, Dangardt F, Gan LM, Strandvik B, Friberg P: High levels of soluble intercellular adhesion molecule-1, insulin resistance and 
saturated fatty acids are associated with endothelial dysfunction in healthy adolescents. Atherosclerosis 2010, 211(2):638-642.

6. Tontonoz P, Spiegelman BM: Fat and beyond: the diverse biology of PPARgamma. Annu Rev Biochem 2008, 77:289-312

7. Matsuzawa Y: Adipocytokines and metabolic syndrome. Semin Vasc Med 2005, 5(1):34-39.

8. Tao J, Sun Y, Wang QG, Liu CW: Induced endothelial cells enhance osteogenesis and vascularization of mesenchymal stem cells. Cells Tissues Organs 2009, 190(4):185-193.

9. Dobrzyn $\mathrm{P}$, Jazurek M, Dobrzyn A: Stearoyl-CoA desaturase and insulin signaling-what is the molecular switch? Biochim Biophys Acta 2010, 1797(6-7):1189-1194.

10. Sampath H, Miyazaki M, Dobrzyn A, Ntambi JM: Stearoyl-CoA desaturasemediates the pro-lipogenic effects of dietary saturated fat. J Biol Chem 2007, 282(4):2483-2493.

11. Ntambi JM, Miyazaki M: Regulation of stearoyl-CoA desaturases and role in metabolism. Prog Lipid Res 2004, 43(2):91-104.

12. Liew CF, Groves $C$, Wiltshire $S$, Zeggini E, Frayling TM, Owen KR, Walker M Hitman GA, Levy JC, O'Rahilly S, Hattersley AT, Johnston DG, McCarthy M: Analysis of the contribution to type 2 diabetes susceptibility of sequence variation in the gene encoding stearoyl-CoA desaturase, a key regulator of lipid and carbohydrate metabolism. Diabetologia 2004, 47(12):2168-2175.

13. Vodyanik MA, Yu J, Zhang X, Tian S, Stewart R, Thomson JA, Slukvin II: A mesoderm-derived precursor for mesenchymal stem and endothelial cells. Cell Stem Cell 2010, 7(6):718-729.

14. Blazsek I, Chagraoui J, Peault B: Ontogenic emergence of the hematon, a morphogenetic stromal unit that supports multipotential hematopoietic progenitors in mouse bone marrow. Blood 2000, 96(12):3763-3771.

15. Muguruma $Y$, Yahata T, Miyatake H, Sato T, Uno T, Itoh J, Kato S, Ito M, Hotta T, Ando K: Reconstitution of the functional human hematopoietic microenvironment derived from human mesenchymal stem cells in the murine bone marrow compartment. Blood 2006, 107(5):1878-1887.

16. Crisan M, Yap S, Casteilla L, Chen CW, Corselli M, Park TS, Andriolo G, Sun B, Zheng B, Zhang L, Norotte C, Teng PN, Traas J, Schugar R, Deasy BM, Badylak S, Buhring HJ, Giacobino JP, Lazzari L, Huard J, Peault B: A perivascular origin for mesenchymal stem cells in multiple human organs. Cell Stem Cell 2008, 3(3):301-313.

17. Hormia M, Lehto VP, Virtanen I: Identification of UEA I-binding surface glycoproteins of cultured human endothelial cells. Cell Biol Int Rep 1983, 7(6):467-475.

18. Nollet F, Kools P, van Roy F: Phylogenetic analysis of the cadherin superfamily allows identification of six major subfamilies besides several solitary members. J Mol Biol 2000, 299(3):551-572.

19. Shimoyama $Y$, Tsujimoto $G$, Kitajima M, Natori M: Identification of three human type-II classic cadherins and frequent heterophilic interactions between different subclasses of type-II classic cadherins. Biochem J 2000 349(Pt 1):159-167.

20. Lampugnani MG, Resnati M, Raiteri M, Pigott R, Pisacane A, Houen G, Ruco $L P$, Dejana $E$ : A novel endothelial-specific membrane protein is a marker of cell-cell contacts. J Cell Biol 1992, 118(6):1511-1522.

21. Breier G, Breviario F, Caveda L, Berthier R, Schnurch H, Gotsch U, Vestweber D, Risau W, Dejana E: Molecular cloning and expression of murine vascular endothelial-cadherin in early stage development of cardiovascular system. Blood 1996, 87(2):630-641.

22. Williams MJ, Sutherland WH, McCormick MP, de Jong SA, Walker RJ, Wilkins GT: Impaired endothelial function following a meal rich in used cooking fat. J Am Coll Cardiol 1999, 33(4):1050-1055.

23. Rudel LL, Parks JS, Sawyer JK: Compared with dietary monounsaturated and saturated fat, polyunsaturated fat protects African green monkeys from coronary artery atherosclerosis. Arterioscler Thromb Vasc Biol 1995 15(12):2101-2110.

24. Staprans I, Rapp JH, Pan XM, Hardman DA, Feingold KR: Oxidized lipids in the diet accelerate the development of fatty streaks in cholesterol-fed rabbits. Arterioscler Thromb Vasc Biol 1996, 16(4):533-538.

25. Nordoy A, Goodnight SH: Dietary lipid and thrombosis: relationship to atherosclerosis. Arterioscler 1990, 10(2):149-163.

26. Shekelle RB, Shryock AM, Paul O, Lepper M, Stamler J, Liu S, Raynor WJ Jr: Diet, serum cholesterol, and death from coronary heart disease: the western electric study. N Engl J Med 1981, 304(2):65-70.
27. Mensink RP, Katan MB: Effect of dietary fatty acids on serum lipids and lipoproteins: a meta-analysis of 27 trials. Arterioscler Thromb 1992, 12(8):911-919

28. Perez-Jimenez F, Castro P, Lopez-Miranda J, Paz-Rojas E, Blanco A, LopezSegura F, Velasco F, Marin C, Fuentes F, Ordovas JM: Circulating levels of endothelial function are modulated by dietary monounsaturated fat. Atherosclerosis 1999, 145(2):351-358.

29. Weigert C, Brodbeck K, Staiger H, Kausch C, Machicao F, Haring HU, Schleicher ED: Palmitate, but not unsaturated fatty acids, induces the expression of interleukin- 6 in human myotubes through proteasomedependent activation of nuclear factor-kappaB. J Biol Chem 2004, 279(23):23942-23952.

30. Ajuwon KM, Spurlock ME: Palmitate activates the NF-kappaB transcription factor and induces IL-6 and TNFalpha expression in 3 T3-L1 adipocytes. J Nutr 2005, 135(8):1841-1846.

31. Krogmann A, Staiger K, Haas C, Gommer N, Peter A, Heni M, Machicao F, Haring $\mathrm{HU}$, Staiger $\mathrm{H}$ : Inflammatory response of human coronary artery endothelial cells to saturated long-chain fatty acids. Microvasc Res 2011, 81(1):52-59.

32. Nichols LA, Jackson DE, Manthey JA, Shukla SD, Holland LJ: Citrus flavonoids repress the mRNA for stearoyl-CoA desaturase, a key enzyme in lipid synthesis and obesity control, in rat primary hepatocytes. Lipids Health Dis 2011, 10:1476-511.

33. Peter A, Weigert C, Staiger H, Machicao F, Schick F, Machann J, Stefan N, Thamer C, Haring HU, Schleicher E: Individual stearoyl-coa desaturase 1 expression modulates endoplasmic reticulum stress and inflammation in human myotubes and is associated with skeletal muscle lipid storage and insulin sensitivity in vivo. Diabetes 2009, 58(8):1757-1765.

34. Dobrzyn P, Dobrzyn A, Miyazaki M, Cohen P, Asilmaz E, Hardie DG, Friedman JM, Ntambi JM: Stearoyl-CoA desaturase 1 deficiency increases fatty acid oxidation by activating AMP-activated protein kinase in liver. Proc Natl Acad Sci U S A 2004, 101(17):6409-6414.

35. Dobrzyn A, Dobrzyn P, Lee SH, Miyazaki M, Cohen P, Asilmaz E, Hardie DG, Friedman JM, Ntambi JM: Stearoyl-CoA desaturase-1 deficiency reduces ceramide synthesis by downregulating serine palmitoyltransferase and increasing beta-oxidation in skeletal muscle. Am J Physiol Endocrinol Metab 2005, 288(3):E599-607.

36. Hardie DG, Pan DA: Regulation of fatty acid synthesis and oxidation by the AMP-activated protein kinase. Biochem Soc Trans 2002, 30(Pt 6):1064-1070.

37. McGarry JD, Mannaerts GP, Foster DW: A possible role for malonyl-CoA in the regulation of hepatic fatty acid oxidation and ketogenesis. J Clin Invest 1977, 60(1):265-270.

38. Dobrzyn A, Dobrzyn P: Stearoyl-CoA desaturase-a new player in skeletal muscle metabolism regulation. J Physiol Pharmacol 2006, 57(Suppl 10):31-42.

39. Lee SH, Dobrzyn A, Dobrzyn P, Rahman SM, Miyazaki M, Ntambi JM: Lack of stearoyl-CoA desaturase 1 upregulates basal thermogenesis but causes hypothermia in a cold environment. J Lipid Res 2004, 45(9):1674-1682

40. Hess D, Chisholm JW, Igal RA: Inhibition of stearoylCoA desaturase activity blocks cell cycle progression and induces programmed cell death in lung cancer cells. PLoS One 2010, 5(6):e11394.

41. Tao J, Shi J, Lu Y, Dou B, Zhou Z, Gao M, Zhu Z: Overexpression of stearoyl-CoA desaturase 1 in bone-marrow mesenchymal stem cells increases osteogenesis. Panminerva Med 2013, 55(3):283-289.

42. Bligh EG, Dyer WJ: A rapid method for total lipid extraction and purification. Can J Biochem Physiol 1959, 37:911-917.

43. Minville-Walz M, Pierre AS, Pichon L, Bellenger S, Fevre C, Bellenger J, Tessier C, Narce M, Rialland M: Inhibition of stearoyl-coa desaturase 1 expression induces chop-dependent cell death in human cancer cells. PloS one 2010, 5:e14363.

44. Scaglia N, Caviglia JM, Igal RA: High stearoyl-coa desaturase protein and activity levels in simian virus 40 transformed-human lung fibroblasts. Biochimica et biophysica acta 2005, 1687:141-151.

doi:10.1186/1476-511X-13-53

Cite this article as: Lu et al:: Overexpression of stearoyl-CoA desaturase 1 in bone marrow mesenchymal stem cells enhance the expression of induced endothelial cells. Lipids in Health and Disease 2014 13:53. 